\title{
AS DIFERENÇAS FINAS: \\ De Simmel a Luhmann
}

\section{Gabriel Cohn}

"Ce sont les nuances qui querellent, pas les couleurs." A frase de Tocqueville (1959, p. 21) bem poderia ter sido adotada por Georg Simmel, o grande mestre na análise dos mais delicados matizes de tom no desenho da vida social. Um desenho que ele não via nos contrastes fulgurantes das cores mas nas gradações, perseguidas até as transições mínimas, no claro-escuro das relações. Talvez não seja demasiado dizer que Simmel parte de uma intuição fundamental, que encontra expressão em um dos seus mais belos ensaios - porque é sempre de ensaios que se trata, como mostrou entre nós Leopoldo Waizbort (1996) dedicado ao tema da gratidão, que será intensivamente usado mais adiante. "As relações mais finas e mais firmes vinculam-se não raro a esse sentimento", escreve ele numa passagem. Os laços mais finos são os mais firmes: Simmel está inteiro aí. Até porque a sua visão visceralmente sociológica está orientada para ver a sociedade na perspectiva das aproximações e dos afastamentos, do jogo sutil das distinções entre o estar mais próximo ou mais longe.
O autor das penetrantes análises do papel do dinheiro na vida social certamente trabalhava num registro muito próprio e muito singular. Nele, tudo aquilo que serviria de referência firme para figuras menores — a sociedade como totalidade abrangente, a integração dos indivíduos no conjunto social, a racionalidade como sentido nítido de cada ação, o cálculo eficaz na troca de equivalentes como paradigma da interação - é posto em questão. Os grandes sociólogos europeus da fase pioneira tinham uma percepção aguda daquilo que percebiam como a dimensão trágica da vida social, pela qual esta é levada a produzir as condições mesmas que irão subtrair aos homens o gozo daquilo que a própria sociedade promete, a começar pela possibilidade de sentir-se nela chez soi. Nisto Simmel nada perde para Weber nem para Durkheim, em quem só uma leitura desatenta ocultaria o tema, oculto na sua linguagem severa mas nem sempre inteiramente reprimido, da nostalgia de uma plenitude impossível, da realização inteira e harmoniosa do social e da personalidade. Tema que, à sua maneira, também ocuparia Simmel. Este, aliás, é o único a nomear explicitamente a tragédia ao examinar a cultura 
como conjunto de formas significativas. É clássica a sua descrição de como o fluxo das experiências humanas inexoravelmente se vê aprisionado em formas fixas que ele mesmo segrega (numa construção cujas afinidades com o contraste habermasiano entre mundo da vida e sistema só fazem aumentar o desconforto pela despreocupação de Habermas com esse seu possível interlocutor, no mínimo para triangular com Luhmann). A despeito dos esforços já feitos, ainda seria uma tarefa fascinante desvendar a fundo a presença desse tom elegíaco na melhor reflexão sociológica da época.

Entre tantas outras coisas, uma era particularmente clara para Simmel. As relações econômicas de troca marcadas pela legalidade racional são insuficientes por si mesmas para estabelecer vínculos duradouros entre os homens. Não bastam, portanto, para constituir uma sociedade, entendida como rede de relações recíprocas sempre renovadas para além do seu impulso inicial. Nisso ele é no mínimo um representante desse "antiutilitarismo negativo" que, na sua recusa a reduzir a ordem social à ordem econômica e contratual, desenharia o terreno comum a toda a Sociologia clássica (Caillé, 1998). Caillé encontra esse traço tanto em Weber quanto em Pareto, em Tocqueville e no primeiro Parsons, e "em Simmel, claro", como ele mesmo salienta. Ainda que de passagem, Simmel acaba assim figurando com destaque como um dos precursores de um movimento atual de recusa do paradigma da troca em nome de um paradigma do dom, cuja paternidade real fica reservada para Mauss.

Certamente se encontrará em Simmel uma crítica aguda a qualquer reducionismo econômico. A última coisa que se poderá buscar nele é algo que lembre o esquema da escolha racional. Nada de individualismo metodológico, mas também nada de holismo. Simmel persegue incansavelmente as mil formas (e aqui já temos um termo carregado) que assume a aproximação sempre assintótica da totalidade, seja no conjunto social, seja nos seus componentes singulares. Estes são indivíduos só na medida em que não têm como realizar-se plenamente como personalidades integrais, assim como as relações entre eles não se completam num todo que seria a sociedade mas se esgotam no conjunto sempre renovado de formas de sociação. Simmel como formulador de um paradigma? Não vamos a tanto. Mas vale a pena revisitá-lo, na companhia daqueles que recusam a centralidade da troca na vida social. Na próxima seção, portanto, examinarei alguns aspectos da obra de Simmel que merecem relevo nesse contexto. Em seguida, numa espécie de salto mortal, buscarei uma conexão, ainda que por contraste, entre a ênfase de Simmel nas formas da vida social e a importância que reveste a dimensão formal na obra contemporânea daquele que aparece como um anti-simmeliano por excelência: Niklas Luhmann. Depois, só me restará concluir.

Difíceis aproximações

A tarefa de Simmel consiste em captar no momento mesmo da sua emergência os processos de sociação, aqueles em que os fluxos da experiência vivida ganham forma e persistem para além dos conteúdos íntimos originais. Feito isso, a demonstração de como essas formas operam na organização das interações é mera decorrência, por mais que ocupe espaço na sua obra. Para dar conta dessa tarefa ele oscila entre dois modelos. O primeiro é de caráter energético. A vida (o fluxo das experiências) aparece como fonte de energia que alimenta as relações recíprocas dos elementos. A sociedade figura aí como um conjunto de aproximações e afastamentos, no quadro dos efeitos da presença desses elementos. A reciprocidade desses efeitos é o traço mais marcante desse modelo. Mas há um outro modelo, não tão nítido mas inseparável do anterior, no pensamento de Simmel. A este, por falta de outro termo, denominarei modelo da impregnação significativa do conjunto das relações entre os indivíduos. Sob esse ângulo, a dimensão significativa impregna a vida social, é o éter em que se movem os homens. "A vida religiosa cria o mundo de novo, ela representa toda a existência numa tonalidade especial", escreve ele em passagem muito expressiva (apud Watier, 1996, p. 36).

Não se pode, pois, reduzir o pensamento de Simmel nem a um modelo da ação significativa, nem a um modelo do 
caráter representacional do simbolismo cultural. Nem Weber, nem Durkheim, mas também não Mauss. O pensamento de Simmel retira seu timbre da ênfase na tensão entre fluxos energéticos e processos de imposição de formas (na mais exata acepção de informação) em ambientes significativos dados. A passagem de um registro da vida social para outro (do religioso para o estético, digamos) aparece como uma modulação do conjunto das experiências numa nova tonalidade. A diferenciação social, o tecido de uma malha cada vez mais fina de relações que aproximam os homens mas os separam na medida mesma em que se multiplicam, é fundamental nessa concepção. Nada de solidariedade social mais cerrada acompanhando a divisão do trabalho, como em Durkheim. Porque não é de interdependência que se trata, mas sim de reciprocidade. E, se a multiplicação de relações coloca os homens em contatos mais freqüentes, ela também introduz novas fontes de assimetria, dificultando os gestos e os sentimentos recíprocos. A resposta para isso é a expansão das obrigações legalmente instituídas e sustentadas, que se impõem sem necessidade de passar pelo interior dos homens. Mas, se isso permite corrigir as insuficiências da reciprocidade espontânea, não é suficiente para criar laços que transcendam a aplicação pontual das obrigações.

É por isso que Simmel não segue o caminho depois trilhado por Parsons, que adotou para o problema da persistência das relações uma solução normativa, e portanto externa aos agentes, por mais que se internalize neles depois. Com mais forte razão ele recusa a posição que encontra em Kant, e poderia assinalar em Durkheim, da valorização do dever como coerção auto-imposta e portanto livre. A liberdade, neste caso, não consistiria em cumprir o dever mas em deixar de fazê-lo; seria puramente negativa, escreve ele no já referido ensaio (Simmel, 1983). E é também por isso que ele é indiferente ao que seria o problema parsoniano básico, da dupla contingência que está na origem de todas as interações e que, para Parsons, só pode ser reduzida pela via do estabelecimento de normas. Parece um paradoxo: Simmel, o mais fino e sensível analista da sempre reiterada dificuldade para assegurar a reciprocidade das ações, é indiferente ao problema da contingência na vida social. A questão para ele não é a das sempre presentes alternativas para as soluções dadas ao problema da interação, mas a de como as formas sociais persistentes e os conteúdos psíquicos fugazes se juntam sem jamais se fundirem. É por isso que, ao invés de prestar atenção à circunstância de que sempre poderia ser diferente, ele, com paciência e paixão de colecionador sempre surpreso com o que encontra, prefere fazer o interminável inventário das formas realmente encontráveis. Isso não significa que ele seja indiferente ao papel do risco na vida social, como uma "dificuldade geral, a priori, de toda ação humana", e a como isso envolve um paradoxo irredutível. "Nossa relação com o mundo e com a vida força-nos a tomar decisões antecipadas; vale dizer, a criar mediante nossa decisão aquelas circunstâncias que deveriam ter sido criadas e conhecidas para permitir-nos tomar a decisão de modo razoável e seguro." (Simmel, apud Wolff, 1964, p. 209).

Numa rica incorporação de um tema que o pensamento romântico havia desenvolvido na Alemanha novecentista, Simmel confere especial relevo à dimensão da espontaneidade na vida social. Nenhuma regulamentação normativa ou legal pode substituir inteiramente os sentimentos que brotam espontaneamente nos homens nas suas aproximações e afastamentos recíprocos. Mas isto não resolve por si mesmo o problema que Simmel detecta na ação puramente racional-calculadora e na mera imposição de imperativos legais. É que em ambos os casos se trata de relações de caráter pontual, que se esgotam na efusão de conteúdos psíquicos, num caso, e no cumprimento da regra, no segundo. A questão é, portanto: como se assegura, na vida social, a continuidade da ação espontânea? (É como se Simmel estivesse ocupado, aqui, com algo como a rotinização da ação espontânea, lembrando o paralelo weberiano em relação ao carisma.) Neste ponto, revelam sua importância as análises que Simmel, na edição da sua Sociologia, reservou para temas que enganadoramente relegou à condição de excursos, como se fossem meras anotações à margem. São temas como a honra, a fidelidade e, especialmente para o que nos importa aqui, a gratidão.

Examinemos um pouco melhor como Simmel analisa a gratidão no ensaio mencionado. "O tom de sentimento 
pessoal e de ação privada que tinge os fatos da gratidão esconde do olhar não adestrado sociologicamente a importância nunca demasiado salientada desses fatos para a vida e a manutenção da sociedade", sustenta ele. A formulação tem um interesse adicional por chamar a atenção para um aspecto negligenciado do modo como Simmel concebe as relações entre as diversas dimensões da vida humana (psíquica, social, cultural) e as relações entre os campos científicos correspondentes. $\mathrm{Na}$ passagem do sentimento íntimo individual à interação social está em jogo também uma mudança de tonalidade. Não há em Simmel qualquer reducionismo psicologista, por mais que ele conceba os conteúdos das interações como da ordem dos sentimentos e dos impulsos subjetivos. (A contrapartida disso é que também não há um formalismo avesso aos conteúdos.) A coloração significativa em que estão imersos os fatos da vida íntima não é da mesma ordem que aquela que infunde seu colorido próprio à vida social. O papel do analista é sempre o mesmo: estar atento às modulações.

A gratidão é inicialmente um complemento da ordem legal. Esta obriga a completar o movimento que, para Simmel, está na base de todas as relações humanas: o "esquema da oferta e do equivalente". Mas nem tudo pode ter sua equivalência assegurada por coerção legal externa. Neste ponto entra a gratidão, para "tecer um laço da reciprocidade, um balanço do receber e do dar entre os homens". O dar e o receber na vida social não podem ser reduzidos à simples troca. Esta não recobre todas as dimensões da reciprocidade entre os homens. Na realidade, quando plenamente desenvolvida, como no mundo moderno, ela dispensa os homens. $\mathrm{Na}$ troca desenvolvida "oferece-se o equivalente objetivo pelo equivalente objetivo, e o homem mesmo, embora evidentemente realize em prol do seu próprio interesse o processo, é na realidade indiferente para este. A relação dos homens converteu-se em relação dos objetos." (Simmel, 1983, p. 211). Neste sentido, a troca é a "conversão em objeto da capacidade de reciprocidade dos homens" (idem, p. 210). A gratidão inverte o sentido desse movimento, voltando-o para o interior dos homens, como "resíduo subjetivo" do ato de receber e dar. E, em mais uma das suas formulações características, Simmel (1983, p. 211) a vê como uma "memória moral da humanidade, uma ponte que a alma sempre encontra para aproximar-se do outro ao mais leve estímulo, insuficiente talvez para gerar por si uma nova ponte". Ao fazê-lo, a gratidão propicia aquilo que importa na constituição e permanência da vida social: a persistência de relações para além do momento da sua criação. Fosse ela extinta como resíduo subjetivo e memória moral, a sociedade "tal como a conhecemos" deixaria de existir.

É verdade que praticamente não há interações em que o receber e o ofertar se mantenham no mesmo nível em ambos os lados, e essa inevitável diferença entre a doação e a contradoação oferece "difíceis problemas éticos e teóricos para o que poderíamos denominar sociologia interior". Claro que aqui entra o dinheiro, como intermediário equalizador. Mas este só opera objetivamente, nas relações entre objetos, ao passo que a gratidão se dirige ao próprio ato da doação, e não apenas à forma monetária que assumem os objetos da troca. Esta, isolada, garante a troca dos objetos, mas não lança as pontes sem as quais a troca perde o sentido, que é social não porque se destaque da intimidade dos homens, mas exatamente porque lança raízes nela. $\mathrm{O}$ ponto fundamental em todos os processos desse tipo é que a persistência diz respeito à relação e não mais ao sentimento que primeiro a propiciou. É como se a gratidão, ou qualquer outro tipo de ponte de ligação dos homens, tivesse a capacidade de converter o seu impulso inicial em um sentimento difuso, tingindo as interações subseqüentes com o tom da gratidão pura e simples, e não com a lembrança pontual de alguma doação singular. É por isso que ela é capaz de suscitar uma contraprestação espontânea mesmo não sendo um dever externamente imposto. Há também um outro caminho para construir essas pontes sociais. Uma relação pode ganhar persistência no tempo não porque tenha na origem algum impulso íntimo, mas porque a experiência reiterada do estar próximos leva os parceiros à "indução" do sentimento correspondente. É o caso da fidelidade, na qual Simmel assinala uma "cooptação" pela situação social externa de mera proximidade dos sentimentos correspondentes. 
Tudo isso nos conduz à questão do papel das formas da vida social em Simmel. A idéia básica é a de que determinados padrões de interação destacam-se dos conteúdos (sentimentos, impulsos etc.) que de certo modo lhes davam vida e passam a operar por sua própria conta, como receptáculos para relações que se ajustem a eles. Isso permite pensar a sociedade não diretamente como um conjunto de interações em fluxo mas como um conjunto de formas padronizadas. Posto isso, as questões passam a incidir sobre as relações das próprias formas entre si (como se relaciona a divisão do trabalho com a competição? e esta com o conflito? e assim por diante) e também sobre as relações entre as formas e os conteúdos que as preenchem no desenrolar da vida social. Na realidade, é este segundo ponto que mais fascina Simmel, como caberia esperar de um autor tão preocupado com a dinâmica da experiência vivida e dos seus modos sociais de organização. Em ambos os casos a ênfase incide sobre a busca de diferenças finas, seja no modo como as experiências se dão nas formas sociais que as condicionam, seja no modo como as formas sociais e culturais assimilam a diversidade das experiências que acolhem. É difícil sustentar que no núcleo do esquema analítico de Simmel esteja uma Sociologia estritamente formal, no sentido de que as formas de sociação sejam vistas como tornando os seus conteúdos irrelevantes para a análise. Há sempre um jogo entre ambas as dimensões, e a referência às formas serve mais para assinalar uma tendência problemática da vida social do que para abandonar o campo dos conteúdos. Uma Sociologia realmente formal exigiria um rompimento radical com a perspectiva do conteúdo e uma completa eliminação das ressonâncias românticas no pensamento de Simmel, a começar pela idéia de tragédia da cultura e pelo seu desdobramento na idéia de uma tensão entre formas de sociação e experiências vividas no âmbito social. Mas talvez seja nessa direção, mais do que qualquer outra, que possamos encontrar linhas de análise para as quais Simmel oferece mais do que parece à primeira vista.

Luhmann e a radicalização da forma
Não é difícil encontrar na teoria social contemporânea aquela radicalização da perspectiva da forma para a qual Simmel ajudou a abrir o caminho mas que não pôde ou não quis realizar. Trata-se, é claro, do esforço de Niklas Luhmann para repensar de alto a baixo os esquemas analíticos disponíveis e redefinir as idéias de ação, forma, sistema, sociedade. Lembremos, para orientar a exposição, os traços básicos da proposta luhmanniana. A sociedade é um sistema que, como todos os sistemas, se define pela diferença que é capaz de manter em relação a um ambiente, que por sua vez inclui outros sistemas. Entre os sistemas incluídos no ambiente da sociedade está o sistema psíquico, cujos portadores são seres humanos. Os homens, portanto, não fazem parte da sociedade mas do seu ambiente. Entretanto, o sistema psíquico não é irrelevante para o sistema social. Pelo contrário, é indispensável. Sem o seu concurso o sistema social teria de absorver níveis de complexidade incompatíveis com o seu bom funcionamento. Isto significa que os problemas que os sistemas têm de enfrentar dizem respeito a duas dimensões básicas: complexidade e funcionamento. Em termos intuitivos, a complexidade de um sistema cresce à medida que aumenta o número de seus elementos e, sobretudo, o número de relações entre eles. Luhmann especifica mais: o limiar da complexidade propriamente dita está dado pelo nível a partir do qual nenhum elemento pode entrar em relação com todos os outros. A complexidade suscita um problema operacional. O sistema precisa funcionar, vale dizer, precisa ser capaz de realizar um conjunto de operações que o mantenham como sistema diferenciado em relação ao ambiente. Essas operações não podem ser em número ilimitado. Portanto, a complexidade do sistema precisa ser limitada também, embora não numa dimensão fixa. Isto significa, em primeiro lugar, que as unidades de funcionamento de sistemas são operações (e não ações) e que todo sistema depende de operações orientadas para manter a complexidade em níveis manejáveis.

Esse problema advém da circunstância de que os sistemas operam em um ambiente que, na sua acepção mais ampla, de "mundo" (mais exatamente, de horizonte de possibilidades), é dotado de duas características básicas: é 
potencialmente ilimitado, no sentido de que oferece um sem-número de possibilidades de relações, e é indeterminado, no sentido de que não oferece por si quaisquer critérios para discriminar entre alternativas. É, em suma, marcado de ponta a ponta pelo seu caráter contingente. Nessas condições, os sistemas, para se manterem como tais, têm de realizar no seu interior duas modalidades básicas de operações. A primeira tem a ver com a redução da complexidade ambiental, mediante seleções entre alternativas que sejam relevantes para o funcionamento do sistema e lhe permitam evoluir ao longo do tempo (ou seja, fixar no seu interior novos traços diferenciadores). A segunda diz respeito à própria capacidade de estabelecer diferenças, sem as quais não há como discriminar nada, num mundo que em princípio é uma multiplicidade possível de eventos contingentes. $\mathrm{O}$ horizonte de possibilidades e as seleções no seu interior são associados, no esquema luhmanniano, à idéia de sentido (que, neste nível, dispensa o concurso direto do agente humano; este fica do lado de fora, oferecendo recursos para as operações significativas) e à idéia de diferença, que em Luhmann não pode ser dissociada da idéia de forma.

Complexidade, contingência, diferença: com base nesses três termos Luhmann constrói todo o seu esquema. Mas o que importa no esquema é a concepção eminentemente dinâmica dos sistemas, que aparecem como entidades operacionais, vistas da perspectiva do seu funcionamento em termos de relações internas e, inseparáveis destas, de relações com o ambiente. Nesse caminho Luhmann reúne condições para inverter a ótica estrutural-funcional parsoniana, ao deslocar a questão de quais as funções requeridas pelo sistema para a questão de como este é levado a responder a exigências funcionais, vale dizer, operacionais de funcionamento. Mas essa radicalização da perspectiva funcional tem conseqüências importantes. A partir do momento em que cabe ao sistema responder a exigências funcionais, e essas exigências derivam de relações com um ambiente marcado pela contingência (incapaz, portanto, de orientar a constituição mais adequada do sistema), este enfrenta uma tarefa nova: a de criar por sua conta os seus próprios elementos, realizar operações autoconstitutivas, para as quais Luhmann adotou o termoautopoiesis. Essas operações necessariamente terão como referência o próprio sistema a que se aplicam. Vale dizer, a auto-referência é uma característica intrínseca a sistemas autopoiéticos; até porque, é voltando-se para dentro que eles se tornam capazes de se abrirem eficazmente (ou seja, seletivamente e sem perder sua diferença) para fora. É um paradoxo, mas não o único no pensamento de Luhmann, e tão intencional quanto os demais. $\mathrm{Na}$ realidade, o paradoxo é a figura central na exposição luhmaniana, e é também o traço central do funcionamento dos sistemas, segundo ele. Simmel também era sensível aos traços paradoxais da vida social. Talvez seja este um bom momento para reunir essas duas desconcertantes figuras.

Seria difícil afastar-se mais de qualquer modalidade do individualismo metodológico do que no esquema de Luhmann; até porque ele é construído de modo a tornar sem sentido contraposições como individualismo/holismo ou mesmo agência/estrutura. No caso de Simmel a distância não é tão grande, mas é plausível supor que o desenvolvimento lógico das suas formulações o levaria na direção de Luhmann e não para qualquer modalidade de análise da escolha racional. (É verdade que um caminho intermediário já foi trilhado, e com interessantes resultados, por Goffman.) Mas é pelo lado da centralidade, tanto em Simmel quanto em Luhmann, da idéia de forma que algumas comparações dos diferentes registros em que ela se torna relevante para a teoria social podem se revelar instigantes; talvez para a sugestão de que, para além do paradigma da troca e do paradigma do dom, haja algo como um paradigma da forma.

Ao preparar-se para discutir um ponto central na sua teoria, Luhmann recorre a uma referência a Simmel:

De acordo com Simmel, a entrada em relações sociais sempre desencadeia um processo de determinação de fronteiras. Mas as fronteiras que Simmel tem em mente não separam o sistema social do seu ambiente. Elas recortam o objeto conforme a seguinte diferença: minha esfera de influência/sua esfera de influência; meus direitos/seus 
direitos; o lado que posso ver/o lado que você pode ver. Desse modo a interação se dá sobre uma fronteira, como num jogo de tênis. Zonas comuns podem ser estabelecidas, e cada qual pode entrar até um certo ponto na esfera do outro. Mas finalmente um domínio íntimo para o outro tem que ser preservado [...] Da perspectiva da teoria dos sistemas essa interpretação considera apenas a referência sistêmica dos sistemas psíquicos. Não se percebe o mundo próprio ao sistema social, em conseqüência da falta do teorema da dupla contingência. (Luhmann, 1995, p. 126)

A distinção está posta. Vejamos como Luhmann concebe o problema.

Tanto Simmel quanto Luhmann têm como ponto de partida uma dimensão problemática da vida social, algo como um dilema fundamental, que tem de ser resolvido de alguma forma para que se possa falar de sociedade. Em Simmel trata-se da relação entre a experiência vivida e as formas que ela assume e que a constrangem. Em Luhmann a questão é a de um dilema básico e sempre reiterado: o da dupla contingência da ação, para usar a terminologia de Parsons, que ele adota neste passo. A tese de Luhmann é de que a dupla contingência conduz diretamente à formação de sistemas sociais. Lembremos do que se trata. Está em jogo o que se poderia chamar o dilema das condições iniciais da ação reciprocamente orientada. Numa situação envolvendo dois agentes que se preparam para agir cada qual conforme a ação do outro (cujas intenções não podem prever), cada agente tem de considerar as possibilidades abertas à sua própria ação e também à do outro. Daí a dupla contingência. Mas, nessas circunstâncias, na falta de qualquer referência que permita orientar os agentes, as ações ficam indeterminadas e não têm como se iniciar. Parsons introduz esse tema para desenvolver sua tese de que a referência em questão seria dada por orientações normativas, por uma sistema normativo compartilhado. Luhmann vai retomá-lo para mostrar que a solução normativa de Parsons é insuficiente e que para enfrentar adequadamente o problema é preciso reformular inteiramente o conceito de sistema na teoria social. Para isso é preciso superar a concepção de sistemas conforme o critério da relação entre as partes e o todo (que, embora implícito, ainda está presente em Simmel). De maneira mais funda e conseqüente do que em Parsons, os sistemas têm de ser vistos como formas de organização capazes de traçar eficazmente fronteiras em relação ao ambiente.

Nestes termos, o sistema não é uma peculiar relação parte/todo, nem meramente um conjunto organizado de elementos, mas uma diferença em relação ao resto, ao mundo, a tudo que possa ocorrer no seu exterior. A conseqüência imediata disso é que nada penetra no sistema sem passar pelas suas operações próprias: o que está fora só se torna relevante, vale dizer, significativo mediante as operações seletivas do próprio sistema auto-referido. Mas essas operações seletivas incidem sobre um conjunto indeterminado de eventos e relações. Cada seleção atualiza, torna relevante (e portanto significativo) para o sistema algo que em princípio não é nem necessário (do contrário não precisaria haver seleção) nem impossível (senão ela seria em vão); enfim, algo contingente. No caso da dupla contingência da ação, quando Parsons introduz os consensos normativos para romper a circularidade das expectativas dos agentes, ele está na realidade apresentando essas orientações normativas como critério para selecionar linhas de ação. Isso muda de figura se considerarmos as seleções como operações internas aos próprios sistemas envolvidos na interação (mesmo que sejam só sistemas de personalidade, na terminologia parsoniana, ou sistemas psíquicos, conforme Luhmann). $\mathrm{O}$ argumento de Luhmann, em poucas e insuficientes palavras, é que a solução do problema da dupla contingência da ação social pode dispensar o recurso ao deus ex machina do consenso normativo parsoniano, desde que se considere que sistemas que operam conforme suas exigências internas podem estabilizar relações de tipo ego e alter (seja qual for a natureza deles) por meio de operações seletivas de caráter específico: comunicações. Claro, dirá o leitor, só que isto apenas transfere o problema para o lado da comunicação. E é verdade. Também a idéia de comunicação deve ser repensada, nesse trajeto.

Dadas as premissas do pensamento de Luhmann já expostas aqui, não será surpreendente lembrar que a comunicação está entre as coisas mais improváveis no 
universo luhmanniano. Como o vôo do besouro, os sistemas de Luhmann não sabem quanto a comunicação é improvável, e se comunicam. Na realidade, fazem muito mais do que isso: criam constantemente no seu interior operações comunicativas, e estas (e não quaisquer partes, incluindo os seres humanos) constituem seus elementos. Vale dizer que os sistemas sociais são conjuntos organizados, auto-referidos e autoconstituintes de operações improváveis de comunicação no interior de ambientes indeterminados marcados pela contingência. As operações comunicativas envolvem três passos: uma informação (ou seja, uma diferença entre algo e o resto), um enunciado e uma operação interpretativa. $\mathrm{O}$ truque consiste em que é possível distinguir o enunciado da informação, de tal modo que a comunicação não é simples transmissão de conteúdos mas é, antes disso, a sensibilização das entidades envolvidas pelo aviso contido no mero enunciado, a saber, o de que há comunicação. Os sistemas sociais são mantidos em condição alerta, por assim dizer, pela reiteração de operações que comunicam comunicação, que avisam que há informação (ou seja, diferenças significativas). Esta informação, contudo, não é transmitida pela comunicação, segundo o modelo emissor/receptor: ela é tornada disponível para possíveis seleções por sistemas ou subsistemas conforme suas operações (portanto, também suas comunicações) internas. Tudo isto envolve sentido, e este depende de seleções entre nequiprováveis. Trata-se de um caso particular, e decisivo na perspectiva dos sistemas, de seleção. O paradoxo, no caso, é que a comunicação envolve simultaneamente redução de complexidade (pela seleção) e aumento de complexidade (ao introduzir informação no sistema).

Mas Luhmann se queixa de que Simmel, ao concentrar sua atenção nas interações, dá como pressuposta a reciprocidade, ignorando a dupla contingência da ação. Além disso, no entender de Luhmann ele não vai além dos sistemas psíquicos e não se dá conta de que a dimensão propriamente social está em outro nível de complexidade, como se a passagem de um nível a outro fosse linear, somente de escala. Não é, diz Luhmann: o trânsito de um a outro exige uma operação peculiar, de acoplamento estrutural. Consiste ela em que um sistema põe à disposição do outro o seu conjunto de operações; a sua própria complexidade, portanto. Isso permite ao sistema social operar (ou seja, usar comunicação) sem precisar reproduzir no seu interior as operações de consciência próprias ao sistema psíquico, por exemplo. Assim, o que é para Simmel uma passagem altamente problemática da experiência vivida (a qual Luhmann denominaria sistema psíquico) para as formas (que em Luhmann corresponderiam ao sistema social), ganha em Luhmann a feição de uma relação sistêmica de caráter estritamente operacional. Parece que eles estão observando os mesmos objetos conforme perspectivas diferentes, se é que se trata de observações. Luhmann diria que é exatamente disso que se trata e, para caraterizar a operação de observação, introduziria a idéia de forma.

Para Luhmann, a expressão forma aplica-se ao resultado de uma operação de decisiva importância para qualquer sistema. Forma significa traçar uma linha que serve de fronteira entre dois lados, dos quais apenas um servirá para posteriores operações. A forma estabelece uma diferença; é isto que é decisivo nela. Neste sentido, o próprio sistema tem uma forma que é a diferença entre sistema e ambiente. Os sistemas particulares se diferenciam segundo o modo como reincorporam no seu interior essa forma básica. No caso do sistema psíquico, Luhmann sugere que essa reincorporação da diferença geral sistema/ambiente assume a forma da diferença entre auto-referência e heterorreferência. Mas o que fundamentalmente importa, aqui, é a concepção geral de forma envolvida.

Toda a ênfase de Luhmann repousa sobre dois pontos. Primeiro, que a forma não é um enquadramento para ações, mas é a condição de operações que individualizam um sistema. Segundo, que a forma nada tem a ver com a formação de identidades mas, pelo contrário, é intrinsecamente uma diferença, e só funciona ao se reproduzir como tal em cada operação do sistema. As formas não são diretamente operações, mas são elas que conferem especificidade às operações próprias a cada sistema, ao se reproduzirem nelas. Talvez se possa 
encontrar nisso uma ressonância da idéia simmeliana de um tom próprio a cada modalidade de manifestação da vida social, mas é claro que a linguagem, e a correspondente busca de precisão, são outras. Luhmann é um observador muito mais distanciado e imperturbável do que Simmel, por mais que este tivesse sido criticado pela sua contemplação meramente estética da vida social. Mas, será Luhmann o observador? Para ele, não se trata bem disso. Os próprios sistemas desenvolvem dispositivos para a observação (como a ciência nos sistemas sociais modernos) para os quais os agentes humanos (como Luhmann) oferecem recursos mas fazem parte do ambiente. Mas o sistema mesmo não é observável sem recorrer à sua forma. E esta só pode ser observada a partir de perspectivas (que podem ser variadas) que permitam perceber ambos os lados da fronteira que ela traçou para estabelecer a diferença básica que exatamente a define como forma. Por seu lado, Simmel é a figura mais acabada do observador atento e inquieto das vibrações da vida social. Mas sua posição separa-o de Luhmann por uma diferença básica: a própria concepção de diferença.

Talvez valha a pena, antes de encerrar, examinar dois casos em que Luhmann trata de temas que evocam fortemente as preocupações de Simmel. Tomemos, para ficar próximos à análise da gratidão de Simmel, a questão da comunicação de estados subjetivos. Para Luhmann (1995, pp. 127-129), um bom exemplo disso, que serve para iluminar facetas importantes da comunicação, é o da sinceridade. O problema é que a sinceridade, ao ser comunicada, torna-se insincera. Dá-se isso devido à distinção entre informação e enunciado que é intrínseca à comunicação, e à circunstância de que tanto a diferença que se enuncia quanto o próprio enunciado são contingentes, poderiam portanto ser outros. Em conseqüência disso, sustenta Luhmann, a comunicação de estados subjetivos desencadeia uma suspeita irremediável, e inevitável numa sociedade como a moderna, que pode ser experimentada como sendo mantida pela comunicação e não por uma ordem natural. Belo exemplo para mostrar que a comunicação luhmaniana não gera um mundo comum de entendimentos, nem mesmo lança pontes entre os homens, como gostaria Simmel. Se ela diz algo sobre quem a emite é antes de mais nada que uma informação está sendo emitida, e que o emissor poderia não emiti-la, ou emitir outra. Da perspectiva do sistema não passa de uma perturbação, de uma "irritação" como diria Luhmann; mas isto basta para o efeito que convém ao sistema, que é o de mantê-lo funcionando.

Tomemos a confiança, que Simmel poderia ver como uma espécie de sentimento complementar à gratidão, na medida em que envolve uma espécie de antecipação moral ao invés de uma memória moral (Luhmann, 1996). Para ele, a confiança - que, sendo contingente como tudo mais, deve ser pensada conjuntamente com a desconfiança corresponde a uma estratégia estabilizadora em condições de risco, ao absorver incerteza. Importante, diz Luhmann, numa formulação quase simmeliana, é que a confiança tem de ser dada livremente (o que, para ele, é sinônimo de contingente). Não pode ser exigida ou normativamente prescrita. Vale pela sua rejeição da alternativa possível da desconfiança. Isso não significa que toda confiança seja espontânea ou, como também diria Luhmann, ingênua. Pode muito bem basear-se na percepção dos riscos envolvidos no seu caráter contingente. Paradoxalmente, é mais estável neste caso, porque incorpora a expectativa do engano, embora tenha a desvantagem de aumentar a complexidade do sistema (Luhmann, 1996, p. 118). Há equivalentes funcionais para ela, como as técnicas racionais dos modelos de tomada de decisão. Mas ela não pode ser reduzida a uma "suposição razoável sobre a qual se possa decidir corretamente". Simmel iria nessa linha? Creio que discreparia em alguns pontos importantes. Não consideraria a confiança do ponto de vista da estratégia, vale dizer, do modo eficaz de orientar decisões em condições de insegurança, mas da capacidade de criar vínculos que transcendam a sua manifestação pontual. Para ele o problema não consistiria na sua condição contingente mas no seu caráter fugaz, que suscita a questão da persistência mais do que a da estabilização de relações.

As formas sociais como enquadramentos gerados pelo fluxo das experiências vividas dos homens, por um lado. As formas como princípios operacionais que permitem distinguir entre si os sistemas, de outro. As totalidades do 
social e do pessoal como problemáticas e sempre empenhadas num fechamento jamais alcançado, pelo lado de Simmel. Os sistemas como entidades que, ao se fecharem eficazmente nas operações que realizam conforme suas formas, ganham condições para se abrirem para um mundo marcado por níveis de complexidade só redutíveis pontualmente, por operações seletivas propiciadas exatamente pelo seu não fechamento, pelo lado de Luhmann. Aproximações e afastamentos entre agentes, por um lado. Dupla contingência como desafio perene para os sistemas sociais, pelo outro. Tonalidades próprias e modulações na passagem de um nível de interações para outro, por um lado. Comunicação sistêmica e acoplamento estrutural, pelo outro. A vida como referência última, como fluxo ilimitado de experiências possíveis, para Simmel. O sentido como referência última, como horizonte ilimitado de experiências possíveis, para Luhmann. Duas linguagens fin-de-siècle na teoria social; com um século de distância, claro. O que as une, no final, é que, por menos que Simmel tematize a questão da contingência da ação, em ambos a referência última é a um campo aberto de possibilidades. Mas dizer isso é também reconhecer que quem, como Simmel, pensa os fundamentos da vida social em termos de fluxos e conforme um modelo energético tende a vedar o acesso a recursos analíticos que estão acessíveis a quem, como Luhmann, os pensa em termos de um modelo de sentido assentado na idéia de um horizonte inesgotável de eventos e relações possíveis. Mas Simmel não se daria por vencido. Apostaria tudo, como o fez, na capacidade de discriminação fina do olhar sociologicamente adestrado. (Ou, como diria ele com um piscar de olhos, na capacidade de detectar diferenças finas mediante as operações internas ao próprio observador humano.) Para Luhmann, resta a tarefa de refinar seus instrumentos.

\section{BIBLIOGRAFIA}

CAILLÉ, Alain. (1988), "Nem holismo nem individualismo metodológicos. Marcel Mauss e o paradigma da dádiva".
Revista Brasileira de Ciências Sociais, Anpocs, 38, pp. 537

LUHMANN, Niklas. (1995), Social systems. Stanford, Stanford University Press.

(1996), Confianza. Barcelona/México, Editorial Anthropos/Universidad Iberoamericana.

SIMMEL, Georg. (1983), "Dankbarkeit. Ein soziologischer Versuch", in G. Simmel, Schriften zur Soziologie, Frankfurt am Main, Suhrkamp.

TOCQUEVILLE, Alexis de. (1959), The European revolution \& correspondence with Gobineau. Garden City, NJ, Doubleday/Anchor Books.

WAIZBORT, Leopoldo. (1996), Vamos ler Simmel? Tese de doutorado, Departamento de Sociologia, FFLCH/USP.

WATIER, Patrik. (1996), "Simmel, religion et sociologie de la religion". Archives des Sciences Sociales de la Religion, 41, 93.

WOLFF, Kurt H. (ed.). (1964), The Sociology of Georg Simmel. Nova York, The Free Press/Macmillan. 